TITLE:

\title{
Exploration of Dopant Species for Lanthanum Polyphosphate
}

$\operatorname{AUTHOR}(S):$

Adachi, Y.; Hatada, N.; Kuramitsu, A.; Uda, T.

CITATION:

Adachi, Y....[et al]. Exploration of Dopant Species for Lanthanum

Polyphosphate. Journal of the Electrochemical Society 2015, 162(6):

F596-F602

ISSUE DATE:

2015-02-18

URL:

http://hdl.handle.net/2433/200707

RIGHT:

(c) The Author(s) 2015. Published by ECS.; This is an open access article distributed under the terms of the Creative Commons Attribution 4.0 License (CC BY, http://creativecommons.org/licenses/by/4.0/), which permits unrestricted reuse of the work in any medium, provided the original work is properly cited. 


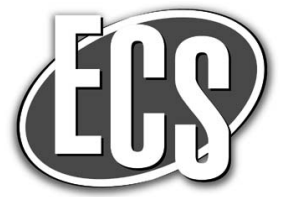

\title{
Exploration of Dopant Species for Lanthanum Polyphosphate
}

\author{
Yoshinobu Adachi, ${ }^{\mathrm{z}}$ Naoyuki Hatada, Akiko Kuramitsu, and Tetsuya Uda
}

Department of Materials Science and Engineering, Kyoto University, Sakyo-ku, Kyoto 606-8501, Japan

Doped lanthanum polyphosphate $\left(\mathrm{LaP}_{3} \mathrm{O}_{9}\right)$ exhibits relatively high proton conductivity. For the practical applications such as the electrolyte of fuel cells, however, its conductivity must be improved by 2 orders of magnitude. Protons are introduced into matrix by lower-valent cation doping, and proton conductivity depends on dopant species. To date, $\mathrm{LaP}_{3} \mathrm{O}_{9}$ has been doped with only $\mathrm{Ca}$, $\mathrm{Sr}$ and $\mathrm{Ba}$. In this work, we tried to dope $\mathrm{LaP}_{3} \mathrm{O}_{9}$ with $\mathrm{Na}^{+}, \mathrm{K}^{+}, \mathrm{Mg}^{2+}$ and $\mathrm{Pb}^{2+}$, as the new dopant species, due to their close ionic radii to $\mathrm{La}^{3+}$. Among them, only $\mathrm{Pb}$ could substitute for $\mathrm{La}$ at a comparable concentration to those of alkaline earth metals and its highest doping level was $6.4 \mathrm{~mol} \%$ (Doping level is defined as the concentration ratio of dopant (M) to host cation (La) site in matrix $(\equiv \mathrm{M} /(\mathrm{La}+\mathrm{M}) \times 100(\mathrm{~mol} \%)))$. Though $\mathrm{Pb}$ can exist as either divalent or tetravalent state, $\mathrm{Pb}$ in $\mathrm{LaP}_{3} \mathrm{O}_{9}$ was identified to be divalent state by XPS analysis. Proton conduction was demonstrated by H/D isotope effect. The electrical conductivity of $\mathrm{Pb}$-doped $\mathrm{LaP}_{3} \mathrm{O}_{9}$ increased with $\mathrm{Pb}$-doping level, owing to the increase in proton concentration. The conductivity of $4.5 \mathrm{~mol} \% \mathrm{~Pb}$-doped $\mathrm{LaP}_{3} \mathrm{O}_{9}$ was about one order of magnitude lower than that of 7.9 mol\% Sr-doped $\mathrm{LaP}_{3} \mathrm{O}_{9}$.

(C) The Author(s) 2015. Published by ECS. This is an open access article distributed under the terms of the Creative Commons Attribution 4.0 License (CC BY, http://creativecommons.org/licenses/by/4.0/), which permits unrestricted reuse of the work in any medium, provided the original work is properly cited. [DOI: 10.1149/2.0821506jes] All rights reserved.

Manuscript submitted January 23, 2015; revised manuscript received March 4, 2015. Published March 18, 2015.

Several lanthanum phosphates exhibit pure and relatively high proton conductivity when doped with alkaline earth metals (e.g. $\mathrm{La}_{7} \mathrm{P}_{3} \mathrm{O}_{18},{ }^{1} \mathrm{LaPO}_{4},{ }^{2-5} \mathrm{LaP}_{3} \mathrm{O}_{9}{ }^{6-10}$ and $\mathrm{LaP}_{5} \mathrm{O}_{14}{ }^{11-12}$ ). Additionally, they have high chemical stability at $200-500^{\circ} \mathrm{C} .{ }^{13-14}$ Owing to these excellent properties, they are regarded as prospective candidates for electrolytes in protonic ceramic fuel cells (PCFCs). Especially, lanthanum polyphosphate $\left(\mathrm{LaP}_{3} \mathrm{O}_{9}\right)$ exhibits the highest conductivity among them $\left(\sim 10^{-4} \mathrm{~S} \mathrm{~cm}^{-1}\right.$ at $\left.400^{\circ} \mathrm{C}^{10}\right)$. For practical use, however, its conductivity must be increased by 2 orders of magnitude.

One of the problems preventing the conductivity enhancement is limited choices of dopant species. Proton conductivity is proportional to concentration and mobility of protons in matrix. Positive defects of interstitial protons are introduced into matrix to maintain electroneutrality, when negative defects are formed by lower valence cation doping. ${ }^{15,16}$ Thus, proton concentration depends on dopant species and increases with dopant concentrations, though dopant concentrations have upper limits which are different by dopant species. ${ }^{4}$ Proton mobility is also dependent on dopant species and dopant concentration. In fact, it has been previously reported that the conductivity of $1 \mathrm{~mol} \% \mathrm{Sr}$-doped $\mathrm{LaP}_{3} \mathrm{O}_{9}$ is 1 order of magnitude higher than that of $1 \mathrm{~mol} \% \mathrm{Ca}$-doped $\mathrm{LaP}_{3} \mathrm{O}_{9}{ }^{7}$ This conductivity difference of $\mathrm{LaP}_{3} \mathrm{O}_{9}$ indicates that proton concentration and/or proton mobility can be different by orders of magnitude, depending on dopant species. To date, however, $\mathrm{LaP}_{3} \mathrm{O}_{9}$ has been doped with only $\mathrm{Ca}, \mathrm{Sr}$ and $\mathrm{Ba}^{7}$ In this study, new appropriate dopant species which can increase concentration and/or mobility of proton has been explored for further conductivity enhancement.

The new dopant species must be monovalent or divalent cations, because they must form negative defects by substituting for $\mathrm{La}^{3+}$. In addition, the doping levels comparable to those of alkaline earth metals should be attained (The highest value ever reported is $7.9 \mathrm{~mol} \%$ by $\mathrm{Sr}$-doping ${ }^{10}$ ). For achieving higher doping levels, the ionic radius of dopant is generally required to be similar to that of host cation. In light of this empirical rule, $\mathrm{Na}, \mathrm{K}, \mathrm{Mg}$ and $\mathrm{Pb}$ were selected as the candidates of the new dopant species in this work $\left(\mathrm{La}^{3+}: 1.16 \AA\right.$, $\mathrm{Na}^{+}: 1.18 \AA, \mathrm{K}^{+}: 1.51 \AA, \mathrm{Mg}^{2+}: 0.89 \AA, \mathrm{Pb}^{2+}: 1.29 \AA$ in eight-fold coordination ${ }^{17}$ ).

For the synthesis of doped $\mathrm{LaP}_{3} \mathrm{O}_{9}$, precipitation method was employed, because it has several advantages over solid state reaction method (SSR) for enhancing the conductivity. For example, higher doping levels can be achieved. ${ }^{10,18}$ Additionally, larger and c-axisoriented grains can be obtained, ${ }^{19}$ while grains are randomly oriented in the case of SSR. Larger grains reduce the density of grain boundary, which generally has an unignorable resistance against proton conduc-

${ }^{\text {z} E-m a i l: ~ a d a c h i . y o s h i n o b u .36 z @ s t . k y o t o-u . a c . j p ~}$ tion, and c-axis orientation enhances the bulk conductivity, because $\mathrm{c}$-axis has one of the highest conductivities in $\mathrm{LaP}_{3} \mathrm{O}_{9}$ crystal. ${ }^{10}$

\section{Charge Carrier Identification}

Monovalent or divalent cation-doping can introduce not only interstitial proton $\left(\mathrm{H}_{\mathrm{i}}^{\bullet}\right)$, but also oxygen ion vacancy $\left(\mathrm{Vo}^{\bullet \bullet}\right)$ and electron hole $\left(\mathrm{h}^{\bullet}\right) .^{12}$ Since $\mathrm{Vo}^{\bullet \bullet}$ and $\mathrm{h}^{\bullet}$ can also function as charge carriers, electrical conductivity $(\sigma)$ is given by the total of the three partial conductivities.

$$
\sigma=\sigma_{\mathrm{H}+}+\sigma_{\mathrm{O}_{2}-}+\sigma_{\mathrm{h}}
$$

Here, $\sigma_{\mathrm{H}+}, \sigma_{\mathrm{O}_{2}-}$ and $\sigma_{\mathrm{h}}$ indicate the partial conductivities of proton, oxide ion and hole.

For the utilization as the electrolytes, the transport number of hole conduction must be $\sim 0$. In this work, these three partial conductions (especially hole conduction) have been discussed, by examining the partial pressure dependence and H/D isotope effect of electrical conductivity.

Partial pressure dependence of conductivity.- The concentrations of $\mathrm{H}_{\mathrm{i}}{ }^{\bullet}{ }^{\bullet}, \mathrm{Vo}^{\bullet \bullet}$ and $\mathrm{h}^{\bullet}$ depend on water vapor and oxygen partial pressures $\left(p_{\mathrm{H}_{2} \mathrm{O}}\right.$ and $\left.p_{\mathrm{O}_{2}}\right) .{ }^{20}$ Especially when the concentration of oxygen ion vacancy $\left(C\left(\mathrm{Vo}^{\bullet \bullet}\right)\right)$ can be regarded as constant (in other words, hydration level is low.), those of interstitial proton $\left(C\left(\mathrm{H}_{\mathrm{i}}{ }^{\bullet}\right)\right)$ and electron hole $\left(C\left(\mathrm{~h}^{\bullet}\right)\right)$ depend only on $p_{\mathrm{H}_{2} \mathrm{O}}$ or $p_{\mathrm{O}_{2}}$, and can be expressed as below.

$$
\begin{gathered}
C\left(\mathrm{H}_{\mathrm{i}}^{\bullet}\right) \propto\left(p_{\mathrm{H}_{2} \mathrm{O}}\right)^{1 / 2} \\
C\left(\mathrm{~h}^{\bullet}\right) \propto\left(p_{\mathrm{O}_{2}}\right)^{1 / 4}
\end{gathered}
$$

If the mobility of each carrier is independent on $p_{\mathrm{H}_{2} \mathrm{O}}$ or $p_{\mathrm{O}_{2}}$, their partial conductivities are expressed as follows.

$$
\begin{gathered}
\sigma_{\mathrm{H}+} \propto\left(p_{\mathrm{H}_{2} \mathrm{O}}\right)^{1 / 2} \\
\sigma_{\mathrm{O}_{2}-}=\text { const. } \\
\sigma_{\mathrm{h}} \propto\left(p_{\mathrm{O}_{2}}\right)^{1 / 4}
\end{gathered}
$$

Thus, the electrical conductivity also depends on $p_{\mathrm{H}_{2} \mathrm{O}}$ and $p_{\mathrm{O}_{2}}$. By examining the partial pressure dependence of electrical conductivity, these conductivities can be deconvoluted.

H/D isotope effect.- Proton conduction can be verified also by examining H/D isotope effect on electrical conductivity. The conductivities of proton conductors in hydrogen atmosphere can be larger 
Table I. Starting materials for synthesis.

\begin{tabular}{lll} 
Material & Purity & Manufacturer \\
\hline $\mathrm{H}_{3} \mathrm{PO}_{4}$ & $85 \%$ & Nacalai Tesque \\
$\mathrm{La}_{2} \mathrm{O}_{3}$ & $99.99 \%$ & Nacalai Tesque or Shin-Etsu Chemical \\
$\mathrm{NaHCO}_{3}$ & $99.8 \%$ & Nacalai Tesque \\
$\mathrm{KHCO}_{3}$ & $99.5 \%$ & Nacalai Tesque \\
$\mathrm{MgO}$ & $99.9 \%$ & Wako Pure Chemical Industries \\
$\mathrm{PbO}$ & $99 \%$ & Nacalai Tesque
\end{tabular}

than those in deuterium atmosphere, owing to the change in the mass of the charge carriers $\left(\mathrm{H}^{+}\right.$and $\left.\mathrm{D}^{+}\right) .^{21}$

\section{Experimental}

Synthesis. - $\mathrm{LaP}_{3} \mathrm{O}_{9}$ and $\mathrm{PbP}_{2} \mathrm{O}_{6}$ were precipitated in homogeneous condensed phosphoric acid solutions, containing lanthanum oxide and hydrogen carbonate of monovalent dopant $(\mathrm{Na}, \mathrm{K})$ or oxide of divalent dopant $(\mathrm{Mg}, \mathrm{Pb})$. The starting materials used for the synthesis are showed in Table I. The detailed procedure is available elsewhere. ${ }^{19}$ First, starting materials were mixed at a proper ratio in perfluoroalkoxy (PFA) beakers or glassy carbon (GC) crucibles, and the mixtures were kept at $190^{\circ} \mathrm{C}$ for several days in air, so as to dissolve solid reagents into phosphoric acid. Then the temperature was raised up to $230-270^{\circ} \mathrm{C}$. By the solutions held at those temperatures in air for several days, $\mathrm{LaP}_{3} \mathrm{O}_{9}$ and/or $\mathrm{PbP}_{2} \mathrm{O}_{6}$ precipitated at the bottom of the crucibles. By washing the precipitates with the hot deionized water $\left(\sim 90^{\circ} \mathrm{C}\right)$, the remaining phosphoric acid solutions were removed from the surfaces of the precipitates.

In the case of the direct precipitation of the dense polycrystals of $\mathrm{LaP}_{3} \mathrm{O}_{9}$ for conductivity measurements, the following procedure was applied using mirror-polished GC crucibles. During the precipitation, the water vapor partial pressure $\left(p_{\mathrm{H}_{2} \mathrm{O}}\right)$ was kept constant at $3.2 \mathrm{kPa}$ by flowing the air, which was bubbled through liquid water kept at room temperature. Then, the temperature was gradually raised from 190 to $250^{\circ} \mathrm{C}$ at the rate of $1^{\circ} \mathrm{C} \mathrm{h}^{-1}$, and then the solutions were held at $250^{\circ} \mathrm{C}$ for four and a half day. After this procedure, plate-like dense polycrystal of $\mathrm{LaP}_{3} \mathrm{O}_{9}$ formed at the bottom of the crucibles.

Characterization.- Phase identification was carried out at room temperature via X-ray diffraction (XRD) analysis on PANalytical $\mathrm{X}$ 'Pert-Pro MPD using $\mathrm{Cu}-\mathrm{K} \alpha$ radiation. The lattice volume was determined by the Rietveld method using X'Pert HighScore Plus software (Version 2.2c). The morphology of precipitates was observed using KEYENCE VE-7800 scanning electron microscopy (SEM).

The compositions of the precipitates were analyzed by energy dispersive X-ray Spectroscopy (EDX) on EDAX Genesis XM2, Wavelength dispersive X-ray Spectroscopy (WDX) on Microspec WDX3PC or inductively coupled plasma atomic emission spectrometry (ICP-AES) on Seiko Instruments SPS3500. An accelerating voltage of $20 \mathrm{kV}$ was used during EDX and WDX analyses. As the standard materials of WDX analysis, $\mathrm{NaPO}_{3}(95 \%$, Wako Pure Chemical Industries) and undoped $\mathrm{LaP}_{3} \mathrm{O}_{9}$ were used. Undoped $\mathrm{LaP}_{3} \mathrm{O}_{9}$ was precipitated at $250^{\circ} \mathrm{C}$ from a phosphoric acid solution with a composition of La:P $=0.8: 15$. It has been reported that the doping level of Sr-doped $\mathrm{LaPO}_{4}$ synthesized by precipitation method depends on precipitation period. ${ }^{18}$ Thus, doping levels in $\mathrm{LaP}_{3} \mathrm{O}_{9}$ were derived from the average compositions of whole precipitates analyzed by ICP-AES.

Valence determination of $\mathrm{Pb}$ was carried out at room temperature via X-ray photoelectron spectroscopy (XPS) analysis on JEOL JPS9010TRX using $\mathrm{Mg} \mathrm{K} \alpha$ radiation. The spectrometer was calibrated using the photoemission line $\mathrm{C}$ 1s (binding energy $285.0 \mathrm{eV}$ ). As a standard material, $\mathrm{PbP}_{2} \mathrm{O}_{6}$ (phosphate of divalent $\mathrm{Pb}$ ) was precipitated from phosphoric acid solution, by mixing the reagents at the ratio of $\mathrm{Pb}: \mathrm{P}=1.5: 15$ and setting the precipitating temperature at $270^{\circ} \mathrm{C}$. The obtained precipitates were ground into powder, and pressed into pellets at $420 \mathrm{MPa}$. Though phosphate of tetravalent $\mathrm{Pb}$ was also tried to be prepared for a standard material, it could not be obtained.

Electrical conductivity measurement. - The electrical conductivity was measured by 2-probe AC impedance spectroscopy in humidified hydrogen atmosphere. For this measurement, $\sim 200 \mu \mathrm{m}$ thick of plate-like dense polycrystals of $\mathrm{LaP}_{3} \mathrm{O}_{9}$ were directly precipitated in phosphoric acid solutions. The obtained precipitates were held at $500^{\circ} \mathrm{C}$ in air for 100 hour to evaporate the remaining phosphoric acid, because it has been recently reported that the remaining phosphoric acid solutions can effect on the conductivity measurement. ${ }^{11}$ After that, Pt was deposited on the both sides of the plates as electrodes by sputtering using Eiko ion coater IB3. During the electrical conductivity measurements, humidified gas mixture of $\mathrm{H}_{2}$ and $\mathrm{Ar}$ was flowed over the samples. The equilibrium oxygen partial pressure $\left(p_{\mathrm{O}_{2}}\right)$ was controlled by changing $p_{\mathrm{H} 2} / p_{\mathrm{H}_{2} \mathrm{O}}$ ratio. $p_{\mathrm{H}_{2} \mathrm{O}}$ was varied from 3.2 to $31 \mathrm{kPa}$, by bubbling the gas through liquid water kept at appropriate temperatures. Especially for the isotope effect examination, $p_{\mathrm{H}_{2} \mathrm{O}}$ and $p_{\mathrm{D}_{2} \mathrm{O}}$ were kept at $5.0 \mathrm{kPa}$, by bubbling the gas through liquid water or deuterium water, kept at 33 or $35^{\circ} \mathrm{C}$, respectively. ${ }^{22}$

\section{Results and Discussion}

The following abbreviations are used in this text. $C_{\text {init. }}$ is the initial concentration ratios of dopant to $\mathrm{La}$ in phosphoric acid solutions $(\equiv \mathrm{M} /(\mathrm{La}+\mathrm{M}) \times 100$, in solutions $) . \mathrm{LP}(\mathrm{M} x)$ is $x \mathrm{~mol} \%$ M-doped $\mathrm{LaP}_{3} \mathrm{O}_{9}$. For example, 5 mol\% $\mathrm{Pb}$-doped $\mathrm{LaP}_{3} \mathrm{O}_{9}$ is $\mathrm{LP}(\mathrm{Pb} 5)$.

Exploration of new dopant species.- In this experiment, the reagents were mixed at the ratio of $\mathrm{La}: \mathrm{M}: \mathrm{P}=0.9: 0.1: 15$ or $0.8: 0.2: 15$ $\left(C_{\text {init. }}=10\right.$ or 20$)$ and $\mathrm{LaP}_{3} \mathrm{O}_{9}$ was precipitated at $230^{\circ} \mathrm{C}$ in air. The powder X-ray diffraction patterns of the obtained precipitates are shown in Fig. 1. Single-phase $\mathrm{LaP}_{3} \mathrm{O}_{9}$ precipitated from every solution in the case of $C_{\text {init }}=10$, while the secondary phases of $\mathrm{NaLa}\left(\mathrm{PO}_{3}\right)_{4}$ or $\mathrm{MgP}_{2} \mathrm{O}_{6}$ precipitated with $\mathrm{LaP}_{3} \mathrm{O}_{9}$ from $\mathrm{Na}$ or $\mathrm{Mg}$-containing solutions, in the case of $C_{\text {init }}=20$. Therefore, the upper limits of $C_{\text {init }}$ for obtaining single phase $\mathrm{LaP}_{3} \mathrm{O}_{9}$ lie between 10 and 20 for $\mathrm{Na}$ - and Mg-containing solutions. In the case of K-containing solutions, the upper limit is larger than 20 , but it might be of the same order as that for Na-containing solutions because $\mathrm{Na}$ and $\mathrm{K}$ are both alkali metals and the existence of $\mathrm{KLa}\left(\mathrm{PO}_{3}\right)_{4}$ has also been reported. The upper limit for Pb-containing solutions will be discussed later.

The concentrations of $\mathrm{Mg}, \mathrm{K}$ and $\mathrm{Pb}$ on the surface of singlephase $\mathrm{LaP}_{3} \mathrm{O}_{9}$ precipitates were analyzed by EDX, and that of $\mathrm{Na}$ was analyzed by WDX. Pb was detected from the precipitate and its local doping level was about $2.6 \mathrm{~mol} \%$, while $\mathrm{Mg}$ and $\mathrm{K}$ were not detected (Fig. 2). Na concentrations were analyzed at 7 points, and the average doping level was $0.7 \pm 0.9 \mathrm{~mol} \%$. (The error was defined as twice the standard deviation). Na doping level is considered to be $\sim 1 \mathrm{~mol} \%$ at most. Thus, only $\mathrm{Pb}$ can substitute for $\mathrm{La}$ in $\mathrm{LaP}_{3} \mathrm{O}_{9}$ at a considerable doping level, among $\mathrm{Na}, \mathrm{K}, \mathrm{Mg}$ and $\mathrm{Pb}$.

Achievable doping level of $\mathrm{Pb}$. - In this experiment, the reagents were mixed at the ratio of $(\mathrm{La}+\mathrm{Pb}): \mathrm{P}=1: 15\left(C_{\text {init. }}=0-60\right)$, and $\mathrm{LaP}_{3} \mathrm{O}_{9}$ was precipitated at $230^{\circ} \mathrm{C}$ in air. The powder $\mathrm{X}$-ray diffraction patterns of the obtained precipitates are shown in Fig. 3 . When $C_{\text {init. }}$ was small $\left(C_{\text {init. }} \leq 50\right)$, single-phase $\mathrm{LaP}_{3} \mathrm{O}_{9}$ precipitated, while the secondary phase of $\mathrm{PbP}_{2} \mathrm{O}_{6}$ precipitated with $\mathrm{LaP}_{3} \mathrm{O}_{9}$ when $C_{\text {init }}$ was larger $\left(C_{\text {init. }}=60\right)$. The compositions of single phase $\mathrm{LaP}_{3} \mathrm{O}_{9}$ were analyzed by ICP-AES (Fig. 4). The Pb-doping level tends to increase with $C_{\text {init. }}$, and reached to $6.4 \mathrm{~mol} \%$ at $C_{\text {init. }}=50$. Though slightly higher $\mathrm{Pb}$-doping levels may be achieved in the range of $50<C_{\text {init. }}<60$, $\mathrm{Pb}$-doping level of $6.4 \mathrm{~mol} \%$ is as high as the maximum Sr-doping level ever reported $\left(7.9 \mathrm{~mol} \%{ }^{10}\right)$.

Valence determination of $\mathrm{Pb}$ in $\mathrm{LaP}_{3} \mathrm{O}_{9}$ - Comparing the XPS spectra of $\mathrm{PbP}_{2} \mathrm{O}_{6}$ and $\mathrm{Pb}$-doped $\mathrm{LaP}_{3} \mathrm{O}_{9}$ (Fig. 5), the binding energies of $\mathrm{Pb}$ 4f 5/2 and 4f 7/2 were accurately matched (144 eV, $139 \mathrm{eV}$ respectively). Based on this result, the valence of $\mathrm{Pb}$ in $\mathrm{LaP}_{3} \mathrm{O}_{9}$ matrix 


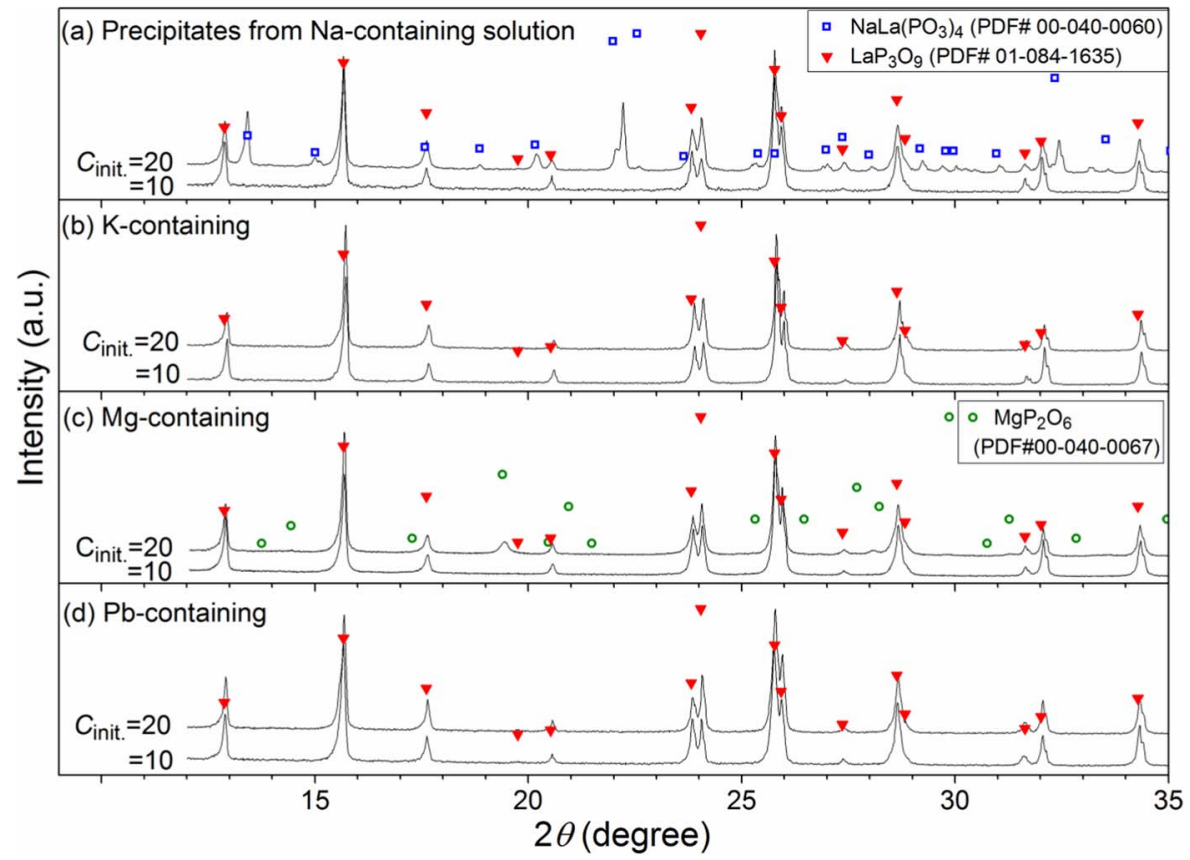

Figure 1. Powder X-ray diffraction patterns of precipitates from phosphoric acid solutions containing (a) $\mathrm{Na}$, (b) $\mathrm{K}$, (c) $\mathrm{Mg}$ or (d) $\mathrm{Pb}$. There were several unknown peaks $\left(\sim 22.2^{\circ}, \sim 33.2^{\circ}\right.$ etc. $)$ in the powder $\mathrm{X}$-ray diffraction pattern of the precipitate from $\mathrm{Na}$ containing solution of $C_{\text {init. }}=20$, and in that from Mg-containing solution of $C_{\text {init. }}=20$, the diffraction peaks attributed to $\mathrm{MgP}_{2} \mathrm{O}_{6}$ can be observed at $\sim 19.5^{\circ}$ and $\sim 28^{\circ}$.

should be the same as that in $\mathrm{PbP}_{2} \mathrm{O}_{6}$, i.e. +2 . However, this result might not be conclusive, because the binding energies of tetravalent $\mathrm{Pb}$ in phosphates are not available.

In order to support the result of XPS analysis, the lattice volumes of undoped and $\mathrm{Pb}$-doped $\mathrm{LaP}_{3} \mathrm{O}_{9}$ are discussed (Fig. 6). The lattice volume increased with $\mathrm{Pb}$-doping level. The ionic radius of $\mathrm{Pb}^{4+}$ is smaller than that of $\mathrm{La}^{3+}$, while that of $\mathrm{Pb}^{2+}$ is larger (Table II). If $\mathrm{Pb}$ existed as $\mathrm{Pb}^{4+}$ in $\mathrm{LaP}_{3} \mathrm{O}_{9}$ matrix, the lattice volume would decrease as $\mathrm{Pb}$-doping level increased. Therefore, this result confirms that the valence of $\mathrm{Pb}$ is +2 in $\mathrm{LaP}_{3} \mathrm{O}_{9}$.

Electrical conductivity.- Morphology of plate-like dense polycrystals.-For conductivity measurement, plate-like dense polycrystals of undoped and $\mathrm{Pb}$-doped $\mathrm{LaP}_{3} \mathrm{O}_{9}$ were directly precipitated from phosphoric acid solutions. The reagents were mixed at the ratios shown in Table III. All of the dense polycrystals were single-phase $\mathrm{LaP}_{3} \mathrm{O}_{9}$ (Fig. 7a). Their $\mathrm{Pb}$ doping levels and relative densities are also shown in Table III, and their relative densities were over $97 \%$.

It was previously reported that the plate-like polycrystals of Srdoped $\mathrm{LaP}_{3} \mathrm{O}_{9}$ had two geometrically different surfaces, upper surface and lower surface. ${ }^{19}$ Upper surface is the plane facing to the solutions during the precipitation, and consists of large columnar grains $(\sim 100$ $\mu \mathrm{m})$. Since the columnar grains are unidirectionally crystallized along c-axis, (001) planes tends to be oriented parallel to upper surface. In contrast, lower surface (facing to the bottom of the crucibles) consists of relatively smaller grains $(<10 \mu \mathrm{m})$, and (110) planes tended to be oriented parallel to this surface.

$\mathrm{Pb}$-doped $\mathrm{LaP}_{3} \mathrm{O}_{9}$ also followed the above characteristics. Orientation can be determined from Fig. $7 b$ and $7 c$, and grain size can be measured using Fig. 8. Additionally, as $\mathrm{Pb}$ doping level increased,

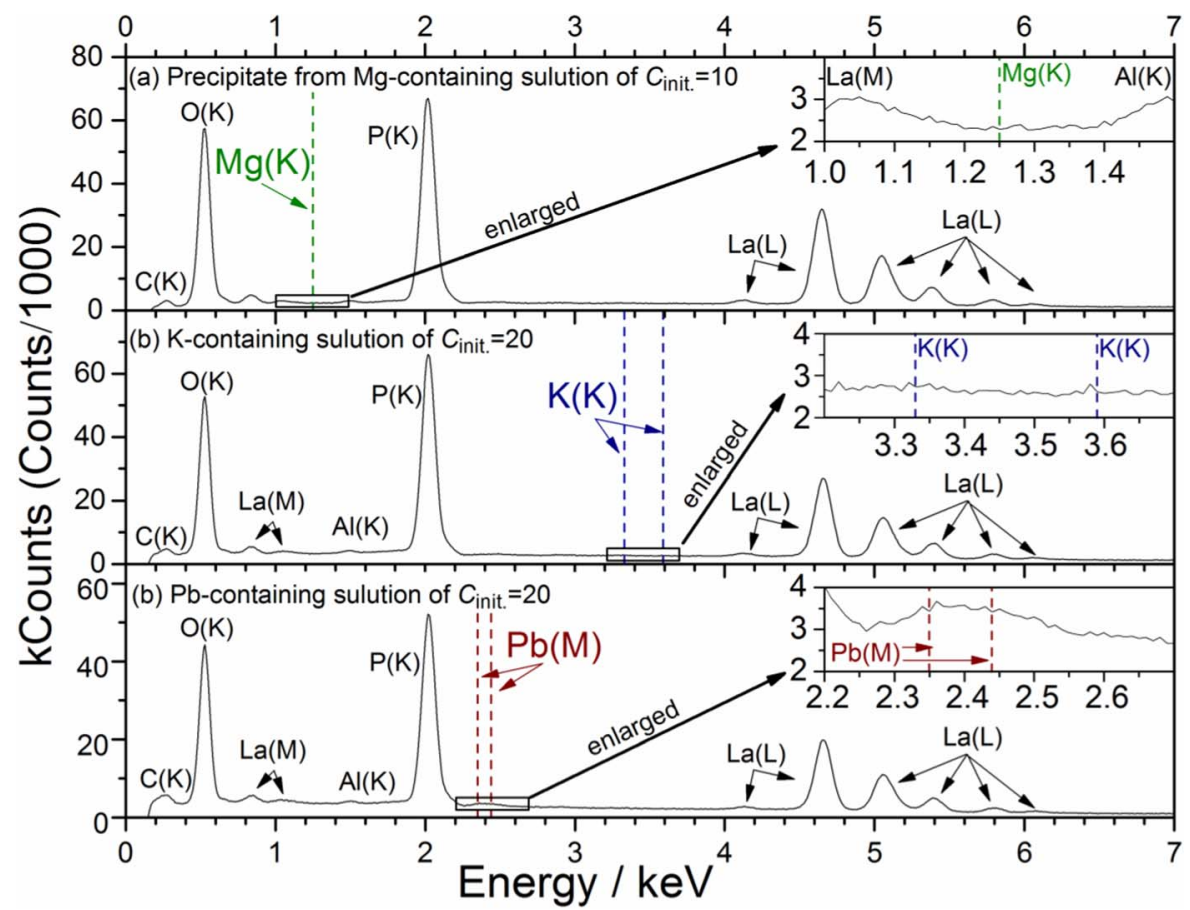

Figure 2. EDX spectra of $\mathrm{LaP}_{3} \mathrm{O}_{9}$ precipitated from (a) $\mathrm{Mg}$-, (b) $\mathrm{K}$ - or (c) Pb-containing solutions. Accelerating voltage, energy step size and total collection time were set at $20 \mathrm{kV}, 10 \mathrm{eV}$ and 1000 second respectively. K-lines of $\mathrm{C}$ and $\mathrm{Al}$ could be attributed to carbon tape and aluminum sample stage respectively. 


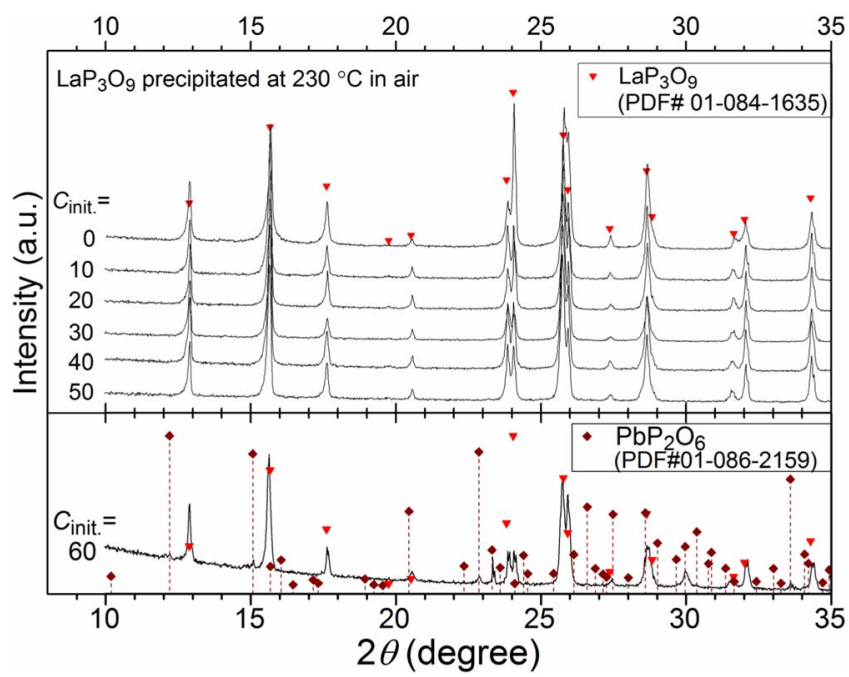

Figure 3. Powder X-ray diffraction patterns of the precipitates from the solutions containing various concentrations of $\mathrm{Pb}$. The patterns of $C_{\text {init. }}=10$ and 20 are the same as those shown in Fig. 1.

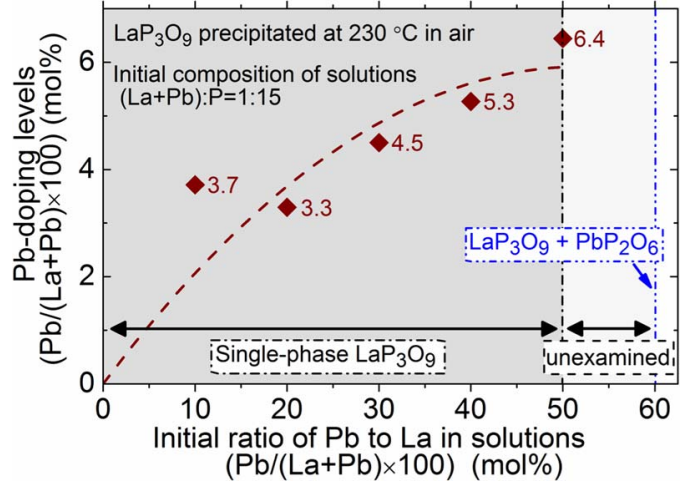

Figure 4. The dependence of $\mathrm{Pb}$-doping level in $\mathrm{LaP}_{3} \mathrm{O}_{9}$ on the concentration ratio of $\mathrm{Pb}$ to $\mathrm{La}$ in solutions.

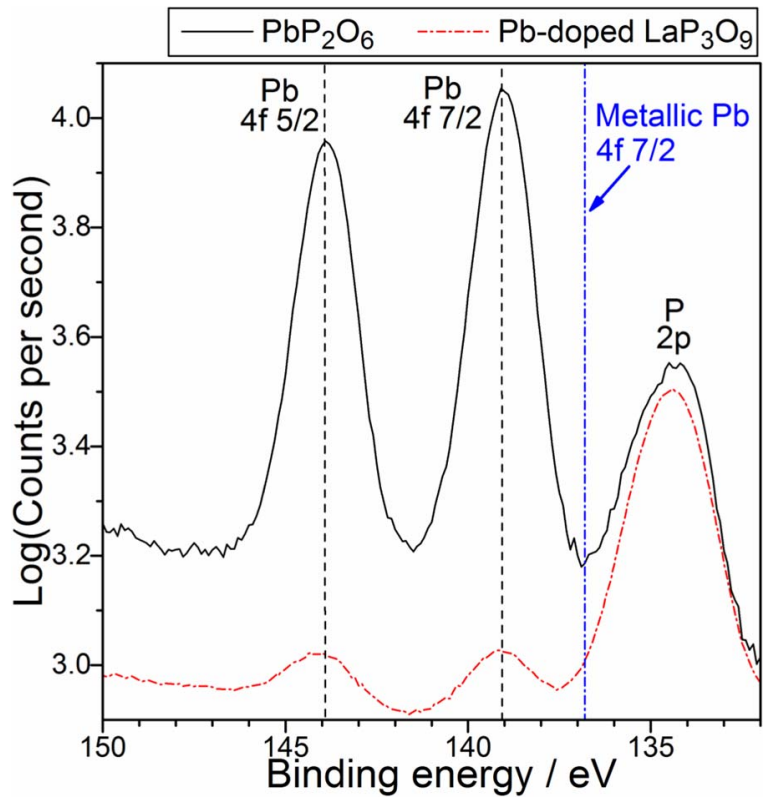

Figure 5. XPS spectra of $\mathrm{PbP}_{2} \mathrm{O}_{6}$ and $\mathrm{Pb}$-doped $\mathrm{LaP}_{3} \mathrm{O}_{9}$. $\mathrm{Pb}$-doped $\mathrm{LaP}_{3} \mathrm{O}_{9}$ was precipitated at $230^{\circ} \mathrm{C}$ from phosphoric acid solutions with a composition of $\mathrm{La}: \mathrm{Pb}: \mathrm{P}=0.8: 0.2: 15$. Though the composition of $\mathrm{Pb}$-doped $\mathrm{LaP}_{3} \mathrm{O}_{9}$ precipitate has not been analyzed by ICP-AES, its $\mathrm{Pb}$ doping level is considered to be $\sim 3.3 \mathrm{~mol} \%$, based on the initial composition of the solution.

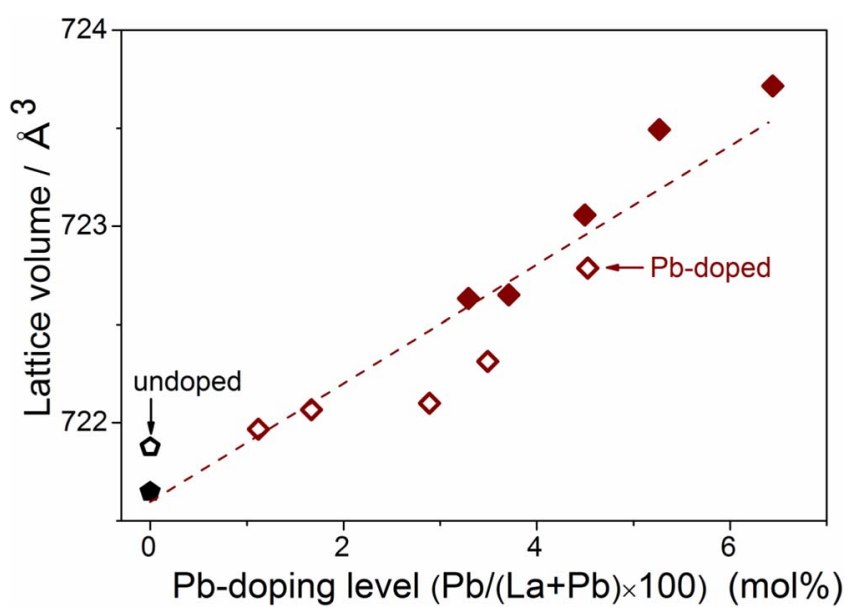

Figure 6. The dependence of lattice volume of $\mathrm{LaP}_{3} \mathrm{O}_{9}$ on $\mathrm{Pb}$-doping level Filled and open symbols represent the lattice volumes of single-phase $\mathrm{LaP}_{3} \mathrm{O}_{9}$ precipitated in air (samples used in the section Achievable doping level of $\mathrm{Pb}$ ) and those precipitated in humidified air (dense polycrystals for electrical conductivity measurement detailed in the section Morphology of plate-like dense polycrystals) respectively.

(001) planes were more strongly-oriented parallel to upper surface, and were almost completely-oriented when $\mathrm{Pb}$ doping level is larger than $2.9 \mathrm{~mol} \%$ (Fig. 7b).

Impedance spectrum.-The impedance spectrum of $\mathrm{LP}(\mathrm{Pb} 4.5)$ is shown in Fig. 9 as a typical example. In the spectrum, there were one clear large arc and unclear arc at low frequency range. The diameter of the large arc was almost independent on hydrogen partial pressure $\left(p_{\mathrm{H} 2}\right)$, and its electric capacitance was calculated to be $\sim 10^{-11}$ F. Based on $p_{\mathrm{H} 2}$-independence, this arc is not attributed to the reaction impedance at the interface between electrolyte and electrode. Then, it should be attributed to either bulk impedance or grain boundaryimpedance. In the case of typical ionic conductor of yttria-stabilized zirconia, the capacitances of the arcs attributed to bulk and grain boundary are reported to be $\sim 10^{-12} \mathrm{~F}$ and $\sim 10^{-9} \mathrm{~F}$ respectively (Section 4.1.3 in Reference 23). Thus, the large arcs in Fig. 9 should be attributed to bulk impedances. The arc attributed to the grain boundary impedance would be too small to be seen, due to the relatively low density of grain boundary (see Fig. 8). Thus, the bulk conductivity can be regarded as the total conductivity, in the case of this sample.

Charge carrier identification.-In the cases of $\mathrm{LaP}_{3} \mathrm{O}_{9}$ doped with alkaline earth metals, their electrical conductivities depend on neither $p_{\mathrm{H}_{2} \mathrm{O}}$ nor $p_{\mathrm{O}_{2}}$, but show H/D isotope effect. ${ }^{6,7} p_{\mathrm{O}_{2}}$-independence indicates a negligible transport number of hole conduction, and the isotope effect indicates a considerable transport number of proton conduction, though the cause of $p_{\mathrm{H}_{2} \mathrm{O}}$-independence has never been clarified. In this manner, $\mathrm{LaP}_{3} \mathrm{O}_{9}$ doped with alkaline earth metals are verified to be an ionic conductor with a considerable transport number of proton conduction. In isotope effect examination, however, one must consider a possibility that if a material has hole conductivity, its electrical conductivity might be different between hydrogen and deuterium atmospheres, depending on the equilibrium oxygen partial pressure. ${ }^{3}$ Thus, with considering that possibility, the partial pressure dependence and isotope effect of electrical conductivity of $\mathrm{Pb}$-doped $\mathrm{LaP}_{3} \mathrm{O}_{9}$ were examined.

Table II. The ionic radii of the several cations in eight-fold coordination. ${ }^{17}$

$\begin{array}{cc}\text { Cation } & \text { Ionic radius / } \mathrm{A} \\ \mathrm{Pb}^{2+} & 1.29 \\ \mathrm{La}^{3+} & 1.16 \\ \mathrm{~Pb}^{4+} & 0.94\end{array}$



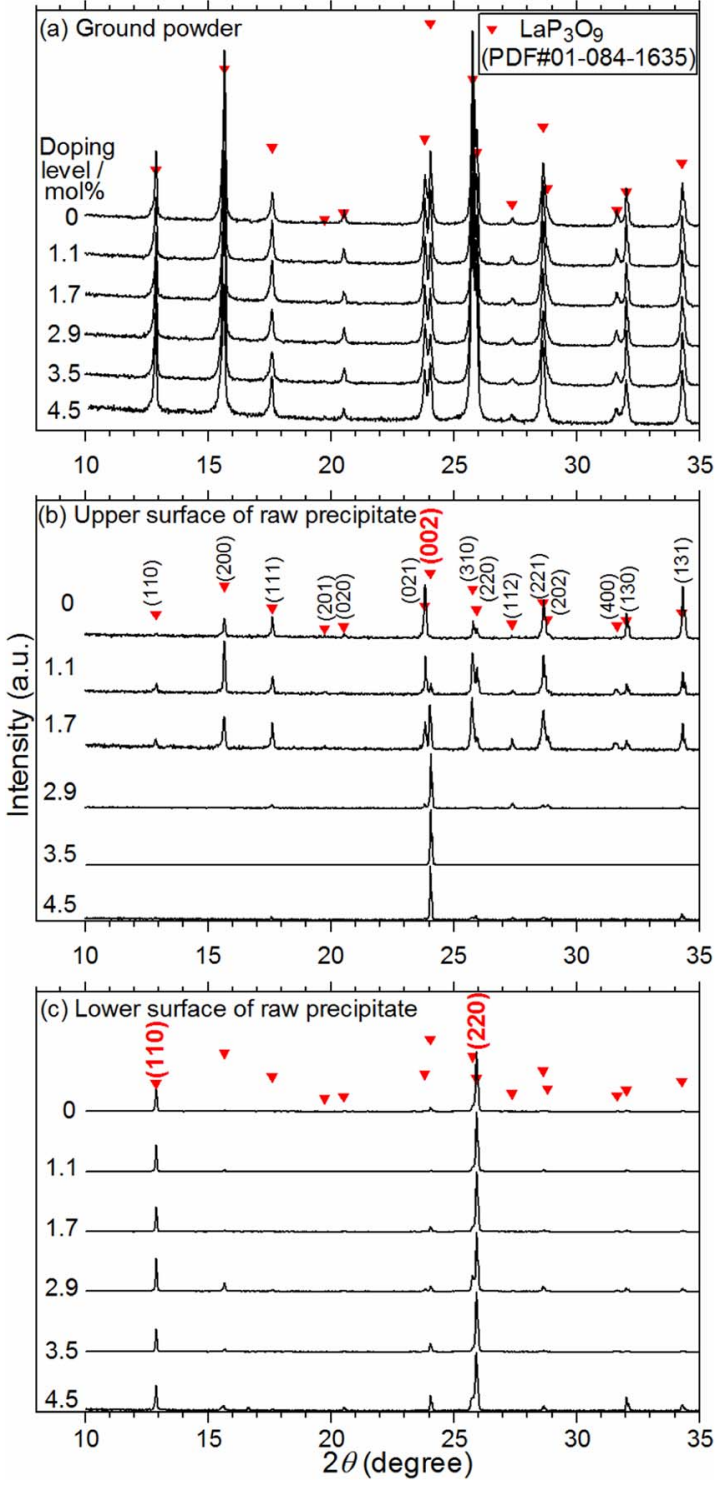

Figure 7. X-ray diffraction patterns of (a) ground powders, (b) upper surfaces and (c) lower surfaces of plate-like dense polycrystals.

As shown in Fig. 10a and 10b, the electrical conductivity of $\mathrm{LP}(\mathrm{Pb} 4.5)$ depends on neither $p_{\mathrm{H}_{2} \mathrm{O}}$ nor $p_{\mathrm{O}_{2}}$. Additionally, as shown in Fig. $10 \mathrm{c}$, the conductivity in hydrogen atmosphere was $\sim 1.08$ times higher than that in deuterium atmosphere. Since the conductivity in hydrogen atmosphere was clearly higher even when $p_{\mathrm{O}_{2}}$ was similar (Fig. 10b), the conductivity difference in isotope effect examination should be attributed to the difference in charge carrier $\left(\mathrm{H}^{+} / \mathrm{D}^{+}\right)$.

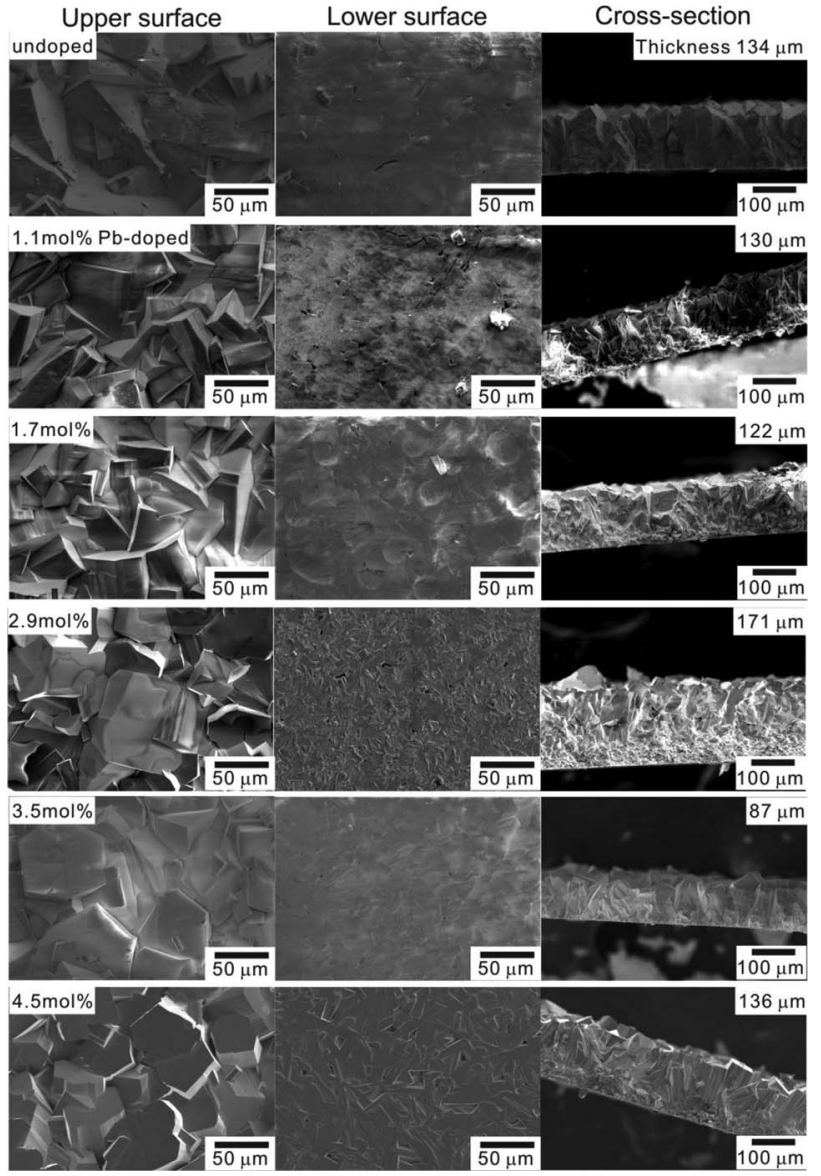

Figure 8. The SEM images of plate-like dense polycrystals of undoped and $\mathrm{Pb}$-doped $\mathrm{LaP}_{3} \mathrm{O}_{9}$. The $\mathrm{Pb}$-doping levels and thicknesses of them are shown in this figure.

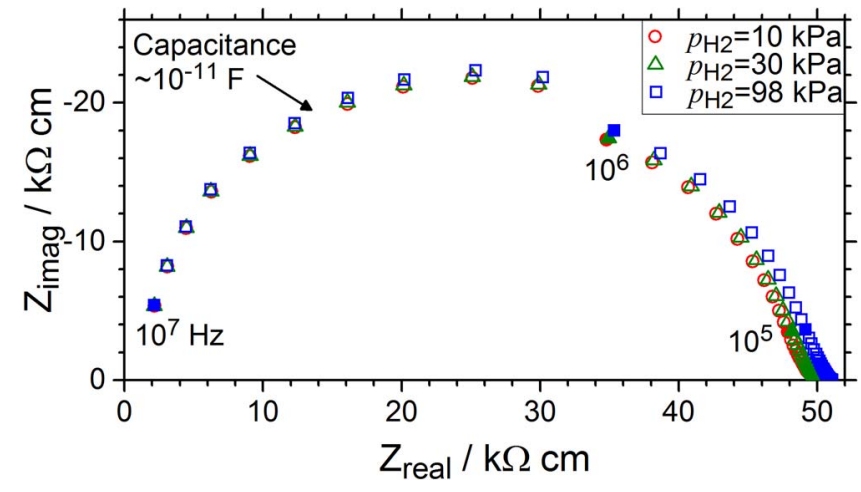

Figure 9. The impedance spectra of $\mathrm{LP}(\mathrm{Pb} 4.5)$ at $400^{\circ} \mathrm{C}$ in humidified hydrogen atmosphere (Ar- $\left.x \mathrm{kPa} \mathrm{H}_{2}-3.2 \mathrm{kPa} \mathrm{H}_{2} \mathrm{O}, \mathrm{x}=10,30,98\right)$.

Table III. Initial compositions of solutions, doping levels and relative densities of plate-like dense polycrystals of LaP $\mathrm{LO}_{9}$. Theoretical density was derived from the lattice volume calculated by Rietveld method and the formula weight in which Pb substitution was taken into account.

Initial compositions of solutions (molar ratio)

\begin{tabular}{ccccccc}
\cline { 2 - 6 } Sample & $\mathrm{La}$ & $\mathrm{Pb}$ & $\mathrm{P}$ & $C_{\text {init. }}$ & Doping level/mol\% & Relative density/\% \\
\hline Undoped & 0.8 & 0 & 15 & 0 & 0 & 1.1 \\
Pb-doped & 0.8 & 0.042 & & 5 & 10 & 1.7 \\
& 0.8 & 0.089 & & 20 & 2.9 & 98 \\
& 0.8 & 0.2 & & 20 & 3.5 & 97 \\
& 0.7 & 0.18 & & 40 & 4.5
\end{tabular}



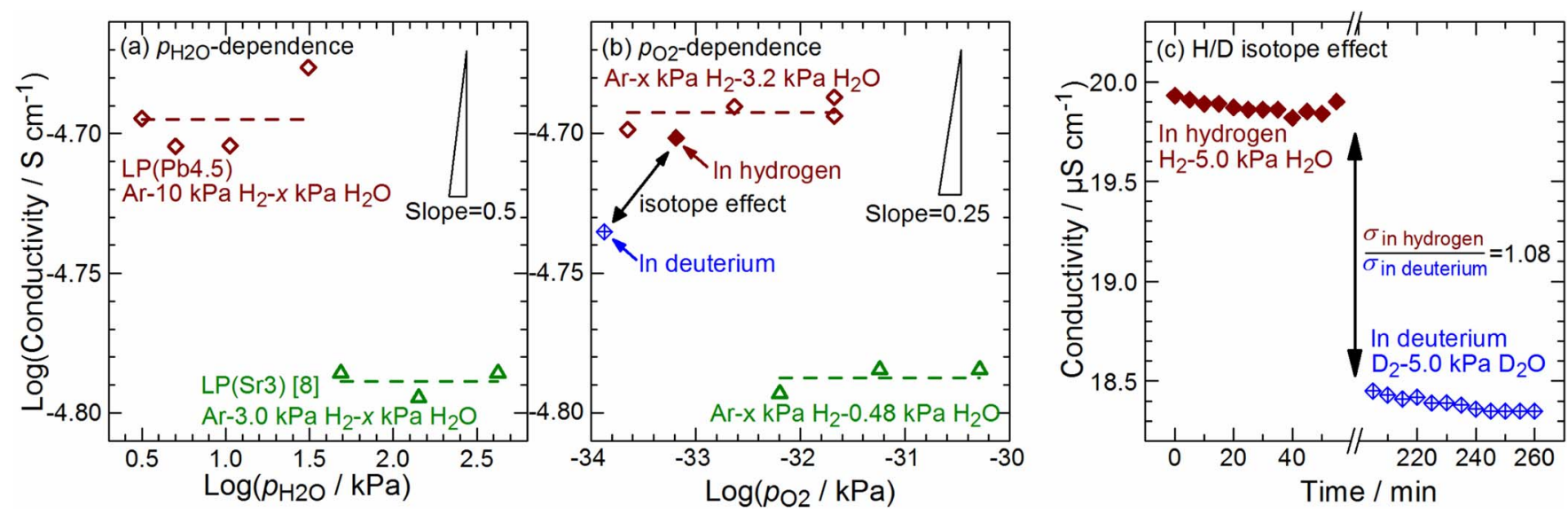

Figure 10. (a) $p_{\mathrm{H}_{2} \mathrm{O}^{-}}$and (b) $p_{\mathrm{O}_{2}}$-dependences of the electrical conductivity and (c) $\mathrm{H} / \mathrm{D}$ isotope effect on the electrical conductivity of $\mathrm{LP}(\mathrm{Pb} 4.5)$ at $400^{\circ} \mathrm{C}$. The conductivities of $\mathrm{LP}(\mathrm{Pb} 4.5)$ and $\mathrm{LP}(\mathrm{Sr} 3)^{8}$ are shown as square and triangle symbols respectively. The slopes shown in (a) and (b) are derived from equation 4 and 6.

Therefore, $\mathrm{Pb}$-doped $\mathrm{LaP}_{3} \mathrm{O}_{9}$ should be an ionic conductor with a considerable transport number of proton conduction.

Dependence of conductivity on $\mathrm{Pb}$ doping level.-The bulk conductivities of undoped and $\mathrm{Pb}$-doped $\mathrm{LaP}_{3} \mathrm{O}_{9}$ are shown in Fig. 11. The conductivities proportionally increased with the $\mathrm{Pb}$ doping level. This conductivity enhancement could be associated with the increase in the proton concentration and/or in orientation strength of grains along c-axis (as mentioned in Morphology of plate-like dense polycrystals section). If it was mainly associated with the increase in orientation strength, the conductivities should have been almost constant when $\mathrm{Pb}$ doping level was larger than $2.9 \mathrm{~mol} \%$, since (001) planes were almost completely-oriented parallel to upper surfaces in that range of doping level. However, the conductivity clearly increased linearly even in that range. Therefore, the conductivity was enhanced mainly by the increase in the proton concentration, which is caused by the increase in $\mathrm{Pb}$ doping level. It should be noted that, in the plate-like polycrystals of $\mathrm{Pb}$-doped $\mathrm{LaP}_{3} \mathrm{O}_{9}$, small gradients of $\mathrm{Pb}$ doping level was seen along the direction normal to the surfaces. In the case of $\mathrm{LP}(\mathrm{Pb} 3.5)$, for example, local $\mathrm{Pb}$ doping level varied from $1.4 \mathrm{~mol} \%$ to $5.0 \mathrm{~mol} \%$. However, we estimated the effect of the doping level gradient on the apparent conductivity and found that the deviation

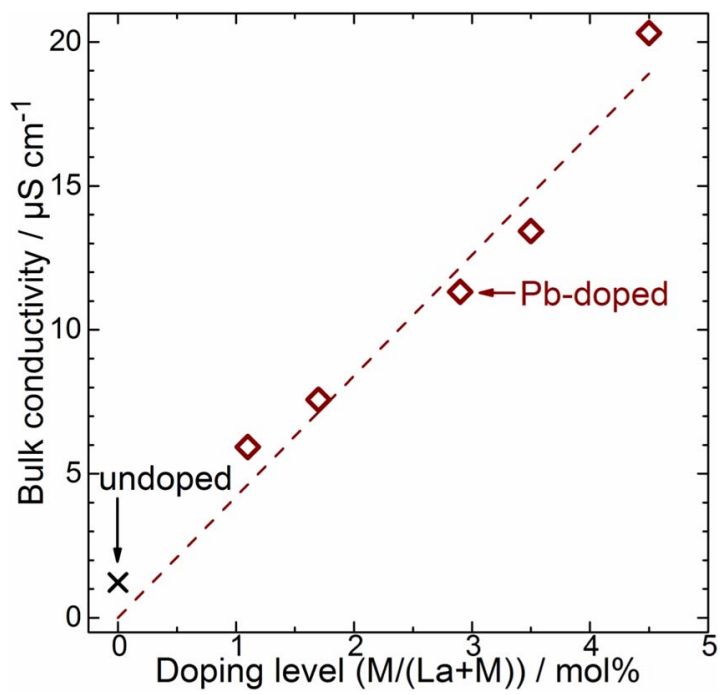

Figure 11. The dependence of the conductivities of undoped and $\mathrm{Pb}$-doped $\mathrm{LaP}_{3} \mathrm{O}_{9}$ on $\mathrm{Pb}$ doping level at $400^{\circ} \mathrm{C}$ in humidified hydrogen atmosphere (Ar-10 $\mathrm{Pa} \mathrm{H}_{2}-3.2 \mathrm{kPa} \mathrm{H}_{2} \mathrm{O}$ ). Cross and square symbols represent the bulk conductivities of undoped and $\mathrm{Pb}$-doped $\mathrm{LaP}_{3} \mathrm{O}_{9}$ respectively. of the apparent conductivity from that of the ideally homogeneous sample was only $10-20 \%$.

Temperature dependence of the conductivity.-The temperature dependence of the conductivity of $\mathrm{LP}(\mathrm{Pb} 4.5)$ was investigated in the range of $200-400^{\circ} \mathrm{C}$ (Fig. 12). In that temperature range, the activation energy of $\mathrm{LP}(\mathrm{Pb} 4.5)$ was calculated to be $0.79 \mathrm{eV}$, and larger than that of $\mathrm{LP}(\mathrm{Sr} 7.9)$ prepared in the similar manner $(0.67 \mathrm{eV}){ }^{10}$ The conductivity of $\mathrm{LP}(\mathrm{Pb} 4.5)$ was about one order of magnitude lower than that of $\mathrm{LP}(\mathrm{Sr} 7.9)$, even though the doping level was only twice lower. Since these two samples have the similar morphologies, the difference in conductivity is not attributed to that in morphology, but to those in proton concentration and/or proton mobility in $\mathrm{LaP}_{3} \mathrm{O}_{9}$ matrix.

\section{Summary}

In this study, it was demonstrated that $\mathrm{LaP}_{3} \mathrm{O}_{9}$ can be doped with $\mathrm{Pb}$ at a doping level of $6.4 \mathrm{~mol} \%$, comparable to those of alkaline earth metals. $\mathrm{Pb}$ substituting for $\mathrm{La}$ in $\mathrm{LaP}_{3} \mathrm{O}_{9}$ matrix was identified to be divalent by XPS, and it was confirmed by the lattice volume change induced by $\mathrm{Pb}$ doping. It was also revealed that $\mathrm{Pb}$-doped $\mathrm{LaP}_{3} \mathrm{O}_{9}$ is

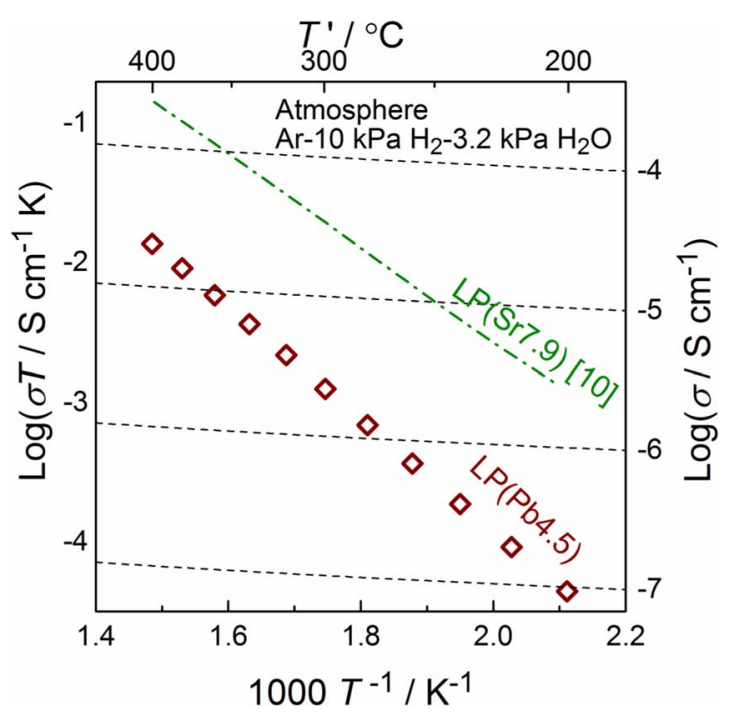

Figure 12. The temperature dependences of the conductivities of $\mathrm{LP}(\mathrm{Pb} 4.5)$ and $\mathrm{LP}(\mathrm{Sr} 7.9)^{10}$ in humidified hydrogen atmosphere $\left(\mathrm{Ar}-10 \mathrm{kPa} \mathrm{H}_{2}-3.2 \mathrm{kPa}\right.$ $\mathrm{H}_{2} \mathrm{O}$ ). 
an ionic conductor with a considerable transport number of proton conduction. Its electrical conductivity increased with $\mathrm{Pb}$ doping level. This trend can be attributed mainly to increase in the proton concentration, rather than to increase in the orientation strength of grains. As far as the authors know, this is the first time for proton conduction to be exhibited by $\mathrm{Pb}$ doping, in proton-conducting phosphates. Unfortunately, the result of electrical conductivity measurement implied that $\mathrm{Pb}$ doping reduce proton concentration and/or proton mobility in $\mathrm{LaP}_{3} \mathrm{O}_{9}$ matrix, compared to $\mathrm{Sr}$ doping. However, it should still be worth trying to dope other rare earth containing materials with $\mathrm{Pb}$ for the conductivity enhancement.

\section{Acknowledgments}

This study was supported by the Elements Science and Technology Project from the Ministry of Education, Culture, Sports, Science, and Technology (MEXT) of Japan. The authors are grateful to ShinEtsu Chemical Co., Ltd for the provision of lanthanum oxide reagent, Yutaka Sonobayashi at Kyoto University for performing XPS analysis and Prof. Yoshitaro Nose at Kyoto University for very useful discussion.

\section{References}

1. K. Amezawa, Y. Tomii, and N. Yamamoto, Solid State Ionics, 175, 569 (2004).

2. T. Norby and N. Christiansen, Solid State Ionics, 77, 240 (1995).
3. N. Kitamura, K. Amezawa, Y. Tomii, T. Hanada, N. Yamamoto, T. Omata, and S. O.-Y. -Matsuo, J. Electrochem. Soc., 152, A658 (2005).

4. K. Amezawa, Y. Tomii, and N. Yamamoto, Solid State Ionics, 176, 135 (2005).

5. K. Toyoura, N. Hatada, Y. Nose, I. Tanaka, K. Matsunaga, and T. Uda, J. Phys. Chem. C, 116, 19117 (2012).

6. K. Amezawa, Y. Kitajima, Y. Tomii, and N. Yamamoto, Electrochem. Solid State Lett., 7, A511 (2004)

7. K. Amezawa, Y. Kitajima, Y. Tomii, N. Yamamoto, M. Widerøe, and T. Norby, Solid State Ionics, 176, 2867 (2005).

8. K. Amezawa, Y. Uchimoto, and Y. Tomii, Solid State Ionics, 177, 2407 (2006).

9. V. Nalini, R. Haugsrud, and T. Norby, Solid State Ionics, 181, 1264 (2010).

10. N. Hatada, K. Toyoura, T. Onishi, Y. Adachi, and T. Uda, J. Phys. Chem. C, 118, 29629 (2014).

11. S. R. Phadke and J. C. Nino, J. Am. Ceram. Soc., 94, 1817 (2011).

12. A. Unemoto, K. Amezawa, and T. Kawada, J. Electroceram., 29, 29 (2012).

13. K. Toyoura, N. Hatada, Y. Nose, T. Uda, and I. Tanaka, Phys. Rev. B, 84, 184301 (2011).

14. N. Hatada, K. Toyoura, Y. Nose, and T. Uda, J. Chem. Thermodynamics, 61, 147 (2013).

15. K. Amezawa, H. Maekawa, Y. Tomii, and N. Yamamoto, Solid State Ionics, 145, 233 (2001).

16. K. Amezawa, H. Takahashi, A. Kuwabara, A. Unemoto, and T. Kawada, Int. J. Hydrogen. Energy, 37, 7995 (2012).

17. R. D. Shannon, Acta Crystallogr., A32, 751 (1976).

18. N. Hatada, Y. Nose, A. Kuramitsu, and T. Uda, J. Mater. Chem., 21, 8781 (2011).

19. T. Onishi, N. Hatada, A. Kuramitsu, and T. Uda, J. Cryst. Growth, 380, 78 (2013).

20. N. Kurita, N. Fukatsu, K. Ito, and T. Ohashi, J. Electrochem. Soc., 142, 1552 (1995).

21. K. D. Kreuer, A. Fuchs, and J. Maier, Solid State Ionics, 77, 157 (1995).

22. R. L. Combs, J. M. Googin, and H. A. Smith, J. Phys. Chem., 58, 1000 (1954).

23. Impedance Spectroscopy Theory, Experiment, and Applications, 2nd ed., E. Barsoukov and J. R. Macdonald, p. 238 Wiley Interscience, New York (2005). 